\title{
Filosofia como atividade não doutrinal em Nietzsche e Wittgenstein $^{1}$
}

Roberto A. P. Barros - Universidade Federal do Pará

Nietzsche: linguagem e crítica da filosofia

\section{Primeiras considerações sobre a linguagem: cursos sobre eloquência e retórica.}

A formulação de uma interpretação da linguagem na filosofia de Nietzsche ocorre paralelamente ao período de elaboração de O nascimento da tragédia. Muito embora haja registros de reflexões anteriores (Crawford, 1988, p. 14), ela se intensifica a partir de 1869, nos cursos que o então jovem professor de Filologia clássica na universidade da Basiléia ministraria pelos dez anos seguintes. Deseja-se aqui abordar a importância desta reflexão e indicar aspectos que podem ser relacionados a ela, com

\footnotetext{
${ }^{1}$ Este artigo foi escrito com o apoio da CAPES e do DAAD, por meio do programa de Intercâmbio científico Brasil-Alemanha de curta duração, do qual participei, nos três primeiros meses de 2014, na Universidade técnica de Dresden (TU-Dresden) e junto ao Professor Dr. Thomas Rentsch.
} 
vistas a sua interpretação possível, de forma central no que diz respeito ao afastamento de Nietzsche da metafísica e à concepção de filosofia como atividade desvinculada a um princípio fixo de verdade.

A atividade docente de Nietzsche como professor de filologia clássica da universidade da Basiléia implicava em cursos referentes tanto à literatura, como à filosofia grega e romana. No período de 1869 a 1879 Nietzsche ministrou numerosos cursos nessas duas áreas, pois em Basiléia lhe cabiam ambas as cadeiras. Textos referentes a estes cursos podem ser encontrados no volume II/1-4 da edição crítica KGB das obras completas de Nietzsche $^{2}$. No que diz respeito à questão da linguagem, os cursos centrais aqui mencionados - cuja datação exata ainda hoje constitui um ponto de especulação (Bornmann, 1997, p. 494) - são: Os líricos gregos (1969) (KGW II/2, pp. 105-182) e Sobre a gramática latina (KGW II/2, pp. 183-310), ambos no semestre de inverno 1869/70, História da eloquência grega (provavelmente proferido no semestre de inverno entre 1872/73) (KGW II/4, pp. 367-411), Apresentação da retórica antiga (possivelmente semestre de verão de 1874) (KGW II/4, pp. 415-502), Esboço da história da retórica (KGW II/4, pp. 505-520). A esses textos deve ser acrescida a tradução do livro I da Retórica de Aristóteles, tema de curso proferido por Nietzsche possivelmente pela primeira vez no semestre de inverno de 1874 (KGW II/4, p.

\footnotetext{
${ }^{2}$ As citações de obras publicadas por Nietzsche mencionadas aqui seguem o padrão já estabelecido no Brasil, com a abreviatura do original em alemão, seguido da abreviatura do original em português, no caso das referências feitas neste texto: Humano demasiado Humano (MA/HH), Aurora (M/A), A Gaia Ciência (FW/GC), Além do bem e mal (JGB/BM), Para a Genealogia da moral (GM/GM), Crepúsculo dos idolos (GD/CI), Fragmento póstumo $(\mathrm{FP})$.
} 
$523)$.

Independentemente da importância da correta datação destes textos, é preciso dar atenção a sua importância teórica em conjunto para a construção de uma interpretação da linguagem em Nietzsche. Nesse sentido, é necessário mencionar determinadas peculiaridades deste material, produzido com pretensões professorais e constituído por apropriações muitas vezes quase que literais de referências científicas da época. Não se trata de um caso isolado, na época de Nietzsche não consistia uma prática esporádica a utilização de fontes justificadoras das posições defendidas nos cursos. No caso desses textos, há várias referências a serem feitas. As mais importantes são certamente a Herder e seu Ensaio sobre a origem da linguagem e a Gustav Gerber, autor do livro Linguagem como arte; de forma mais indireta, os trabalhos de Wilhelm Von Humboldt. Com efeito, essas influências se deixam claramente evidenciar na parte introdutória do curso sobre a gramática latina, intitulada Da origem da linguagem. Nietzsche começa a preleção com uma advertência, de que deseja já de início indicar como a linguagem não deve ser pensada. A isso se segue a afirmação de que a linguagem não é uma construção consciente, de um indivíduo ou de uma coletividade, pois o próprio pensar consciente apenas é possível por meio da linguagem (KGW § 1, p. 185). Em seguida, indicando a inclinação para uma leitura orgânica da linguagem, Nietzsche afirma: "O conhecimento filosófico mais profundo já se encontra preparado na linguagem" (Bertino, 2011, p. 9).

Nos cursos ministrados no início da década de 70, a temática central se altera. A consideração da linguagem volta-se para a acentuação da vinculação entre uso linguístico e a dinâmica político-social (Lopes, 2006, p. 42). Esta perspectiva é central 
na consideração de Nietzsche sobre a retórica, e perpassa todos os textos até o curso sobre a retórica de Aristóteles. Nos apontamentos para o curso sobre a história da eloquência grega, Nietzsche menciona a retórica como uma criação laboral grega (KGW II/4, p. 368), a partir da valoração excessiva da fala no seu período democrático. Nessas sociedades, prioritariamente nas colônias, a fala significava o mais alto poder e meio de comunicação inter pares (Ibid., p. 369). Daí surge, para Nietzsche, a sofística, inicialmente com Protágoras, em 455 a. C., e que tem por finalidade, mediante o uso dialético da linguagem, a alteração da forma de consideração das coisas e a superação de todas as outras ciências. Com ela se altera também a forma grega de expressão. Esta deixa de ser literária e retorna à oralidade, e então constitui uma forma nova de expressão linguística (Ibid., p. 385). Segundo Nietzsche, a eloquência e o estilo artístico da fala tiveram seus ápices com o elitista Demóstenes, em Atenas, e o seu ocaso com Dinarchus de Corinto (Ibid., p. 397), devido a sua redução à reprodução e à imitação. Independentemente disso, a influência da eloquência se estendeu até os romanos, e com estes Atenas se tornou para a retórica "apenas um local do seco adestramento profissional" (Ibid., p. 411).

A interpretação da retórica como associada a práticas institucionais gregas é reconfirmada no curso de 1874, intitulado Apresentação da retórica antiga, onde Nietzsche, novamente tomando a sociedade democrática grega como local de nascimento dessa disciplina, a associa - seguindo a interpretação aristotélica - à prática jurídica, e declara que sua finalidade seria a de convencer (Überreden), e não de ensinar (belehren) (KGW II/4. p. 415). A retórica é "essencialmente uma arte republicana" (Ibid.), ela se torna a mais elevada atividade do homem político 
cultivado e é analisada por Nietzsche a partir de três figuras fundamentais, Górgias, Isócrates e Aristóteles.

O texto se inicia com a menção à tradicional oposição entre filosofia, retórica e, por conseguinte, sofística. Segundo Nietzsche, estabelece-se com Platão a oposição entre estas formas de comunicação. Com o filósofo grego é primeiramente colocado e consolidado o princípio da má finalidade da retórica, devido a sua carência filosófica (Ibid., § 1, p. 419). Mas, segundo Nietzsche, Platão não desejava destruí-la, apenas colocá-la a serviço da filosofia. As primeiras dificuldades entre ambas surgem disso, pois Platão busca condicionar a retórica à boa finalidade proposta pela filosofia. Essa tensão pode ser compreendida, segundo ele, nas duas obras mais antigas sobre a retórica. No escrito "Rhetorica ad Alexandrum", cuja questão da autoria não é problematizada por Nietzsche, no qual a retórica, dissociada de Aristóteles, é concebida tendo em vista o uso prático e não filosófico, expressando desse modo nos ensinamentos de Isócrates e por isso não apresentando nem mesmo uma definição de retórica (KGW II/4, § 1, p. 419). A outra obra, a Retórica de Aristóteles, puramente filosófica e que exerce decisiva influência em todo conceito posterior de retórica. Segundo Nietzsche, com Aristóteles se estabelece a perspectiva da retórica como atividade, que poderia ser elevada a uma técnica (Ibid.). Ele a divide em acidental e essencial, em uma interpretação segundo a qual, a apresentação (Vortrag) se torna a parte acidental, pois a sua visão dela é livresca e não oral e, por isso, Aristóteles não percebe a impossibilidade de um uso não retórico da linguagem (KGW II/4, § 3, p. 425).

É primordialmente uma forma de apresentação de uma excitação nervosa (Nervenreiz) e nunca está relacionada à coisa 
mesma (Ibid.). A ideia de uma língua pura decorre do desenvolvimento do sentido linguístico de um povo, em grandes sociedades, e se refere fundamentalmente a algo não excepcional. "O puro é o não excepcional" (KGW II/4, § 4, p. 428). Ela surge apenas em línguas bem acabadas.

Na retórica há também a perspectiva de uma imitação da natureza, mas esta é pensada apenas no sentido de convencer o ouvinte da verdade das coisas representadas (Ibid., § 5, p. 434). Outros aspectos seus são o caráter agonístico, ao qual está associado o estético, pois "o combatente não se distingue apenas pela força, mas também pelas armas brilhantes" (Ibid.). Nietzsche indica nestes cursos que a ideia de uma pureza (Reinheit) da fala é uma concepção posterior, estranha ao uso linguístico efetivo, e que estaria associado à filosofia. Nos sofistas, essa concepção inexiste. Górgias desejava associar sua oratória ao estímulo (Reiz) dos poetas, ainda que em oposição ao uso habitual da retórica na escola isocrática.

\section{A perspectiva fisio-psicológica}

Em clara consonância com o espírito do neokantismo alemão, com o qual Nietzsche entra em contato direto por intermédio de Friedrich Albert Lange, precursor do neokantismo (Crawford, 1988, p. 68), e de Gustav Gerber, a tendência de sua interpretação da linguagem tende cada vez mais para argumentos relacionados a dados tomados das ciências naturais. Nietzsche demonstra ter assimilado a tendência de interpretação dos dados da sensibilidade que norteou significativamente a especulação psicológica na Alemanha na segunda metade do século XIX (Lambert, 2000, p. 23). No seu ensaio Sobre a verdade e a mentira em sentido extramoral, de 1873, publicado postuma- 
mente e decisivamente influenciado pela leitura de Schopenhauer e de Gerber, o tema do estímulo nervoso (Reiz) apresenta-se de forma central. A origem das palavras deve ser remetida a esse princípio, à relação entre sensibilidade e coisa, e, em seguida, à transposição desse estímulo num som, por meio de metáforas. A linguagem é produto do orgânico e não instrumento de uma racionalidade que a molda. A interpretação de Nietzsche indica uma dependência do intelecto com respeito à linguagem, no que se refere à forma de como este organiza e interpreta o mundo. Em última análise, as categorias lógicas podem ser entendidas como categorias linguísticas, as quais seriam, por sua vezes, remetidas a fatores condicionantes de ordem biológica.

Nessa interpretação, a Linguagem é um instrumento do organismo, e a finalidade última deste é a expansão. É um instrumento metafórico dessa tendência, e jamais se constituiu como um pressuposto do conhecimento verdadeiro (Lopes, 2006, p. 74). Interpretar o existente através de princípios que são, em última análise, inerentes apenas ao uso linguístico, significa se deixar seduzir pela filosófica mitologia da linguagem (MA II/HH II, "O andarilho e sua sombra" $§ 11$ ), que pressupõe a crença no sujeito (M/A § 116) e nos objetos estáveis, na matéria, em linhas, pontos e substancialidades, princípios que em última análise podem ser remetidos a pressupostos linguísticos. A teoria pulsional e a interpretação da linguagem caminham então juntas (M/A § 119), e buscam oferecer uma interpretação da linguagem no contexto da teoria da vontade de poder (GM/GM I § 2), e, por meio disso, tornar desnecessária a questão do fundamento. 


\section{Moral e genealogia}

Os escritos da segunda metade da década de oitenta dão continuidade a uma via interpretativa da moral, que Nietzsche iniciara com Humano, demasiado humano (MM I/HH I) e Aurora $(\mathrm{M} / \mathrm{A})$, a saber, a análise crítica dos valores morais basilares da cultura ocidental (GM/GM, prefácio, § 2). Em Para além de bem e mal e Para a genealogia da moral Nietzsche não se contenta com a elucidação do papel exercido pelos pressupostos valorativos das tábuas de valores da cultura, deseja analisar a moral em um sentido extra-moral (Lampert, 2001, p. 147). Ele ambiciona elucidar seu processo de proveniência, sua gênese, mas não fazendo uso de pressupostos teóricos ou transmundanos (GM/GM, prefácio § 3), mas de dados efetivos, ainda presentes no horizonte valorativo do Ocidente. A abordagem destes aspectos deve distanciar-se das formas tradicionais de consideração, pois com ela se deseja problematizar o próprio valor da moral (Ibid., prefácio, § 5) e não discuti-la como algo determinável. Esta questão se revela propriamente como um problema moral, de atribuição, de perspectiva de valor, concernente à própria moral. A nova tarefa não é tentar refundamentar a moral de modo mais rigoroso (Witzler, 2001, p. 137), mas mostrar que este é apenas um problema aparente (Scheinproblem), que decorre da moralização da linguagem (M/A § 47).

Nessa perspectiva, aspectos linguísticos desempenham uma função significativa. A compreensão da efetiva significação e amplitude do uso da linguagem desvela a força atuante do dogmatismo da tradição filosófica, que com ela transforma as mais rudimentares intuições e crenças populares - como a estabilidade do eu e do sujeito - em problemas filosóficos (JGB/BM, prefácio, KSA 5, p. 12). Os filósofos acreditam nessas estabili- 
dades porque se deixaram enredar nas teias da linguagem (FP: KSA 7, verão de 1872, 19 [135], 463). A passagem inicial do breve prefácio de Para além de bem e mal indica a manutenção do ponto de vista já evidenciado nos escritos anteriores, que pressupõe a linguagem como forma de expressão e não como veículo de transmissão de alguma verdade ou conhecimento independente (Pinheiro, 2011, p. 249). Outro ponto significativo revela a indicação da sua força de sedução (Verführung), que pressupõe a adequação de pressupostos filosóficos a aspectos estruturais do uso linguístico (JGB/BM § 34). Todavia, para Nietzsche, a filosofia, o pensamento racional e a linguagem estão definitivamente vinculados à atividade instintiva. Por meio da teoria pulsional, a própria filosofia pode ser entendida em última análise como o autoconhecimento de seu autor (Urheber) e nunca como uma atividade independente, voltada à verdade e ao conhecimento. Vinculada ao instinto, a filosofia é busca por domínio (Herrsuchtlich) (JGB/BM § 6) e, desse modo, é impulso tirânico, forma espiritual da vontade de poder, mas que moralizada, voltou-se à "criação do mundo" como causa prima (JGB/BM § 9). Por esse motivo, sempre que se tentou pensar cientificamente a moral, os filósofos cogitaram sua fundamentação (Begründung) e não a coleta de material, as versões conceituais, a organização de um monstruoso reino de percepções e diferenças de valor, a partir dos quais a vida cresce procria e morre. Estes seriam os pressupostos corretos para se pensar cientificamente a moral e então tornar "visíveis as configurações mais recorrentes e frequentes destas cristalizações da vida", enquanto preparação para um "ensinamento tipológico da moral" ( Typehlehre der Moral) (BM § 186). Por este motivo, os filósofos ficaram sempre restritos a uma "forma erudita de boa fé na moral dominante" 
(Ibid.).

A interpretação genealógica da moral pressupõe o operador teórico da vontade de poder (Lampert, 2001, p. 149). Ele é pensado como antípoda de toda reflexão acerca da moral efetuada pelo platonismo e pelo cristianismo, como oposição a toda consideração da moral que a pressupõe como valor absoluto. $\mathrm{O}$ pressuposto da vontade de poder reinterpreta a moral como arbitrariedade contra os impulsos, como "oposição a todo laisser aller, um pouco de tirania contra a "natureza", também contra a "razão" (JGB/BM § 188). "Razão" e "natureza" humanas se aproximam enquanto produtos dos impulsos. Não é preciso recair no equívoco metafísico de tentar defini-las, ambas são pensadas a partir da própria forma de manifestação da vontade no mundo. A tirania da moral repousa na delimitação de uma forma aceitável de impulso, cuja justificação decorre do poder que estabelece a forma de manifestação pulsional de seu interesse.

Genealogia da moral significa a compreensão fisio-psicológica do processo de proveniência das formas morais de valoração, que foram assimiladas e tornadas canônicas na cultura ocidental. Ela é um desdobramento da transvaloração de todos os valores pretendida por Nietzsche, cujo primeiro estágio é precisamente a superação (Überwindung) (JGB/BM § 32), o tornar evidente a falsidade e fragilidade de toda essencialização, de toda absolutização moral, da moral tornada princípio em si mesma. No domínio linguístico, significa compreender tanto a proveniência metafórica, como a proveniência arbitrária e moral das palavras e designações (GM/GM I, § 4). O estudo etimológico se contrapõe a toda interpretação metafísica da atribuição de nomes e de seu significado, portanto a toda perspectiva do valor inerente de coisas e palavras. Estas duas perspectivas podem, então, ser 
entendidas como advindas da moralização da verdadeira função e finalidade do uso linguístico, a exteriorização pulsional com pretensões de domínio. A análise fisio-psicológica lhe revela o caráter fetichista, do qual decorre tanto a crença na identidade das coisas e do sujeito, como as categorias filosóficas, que então, relacionadas a uma racionalidade tornada divina, aspiram pela eternidade. Desse modo, mesmo Deus deve ser entendido como produto da linguagem, e o primeiro pressuposto para que possa pensar além da moralização do desejo de eternidade é a superação da essencialidade das categorias gramaticais (GD/CI, "A 'razão' na filosofia', § 5).

\section{A questão linguística e filosofia não doutrinal em Wittgenstein}

\section{Recepção da filosofia de Nietzsche por Wittgenstein}

Partindo-se dos resultados da pesquisa de Marco Brusotti acerca da recepção de Nietzsche por Wittgenstein, é possível mencionar pelo menos dois momentos da mesma. Uma primeira leitura, em 1914, possivelmente de $O$ anticristo, mas também de A genealogia da moral e Para além de bem e mal, marcada pelo interesse pela transvaloração dos valores e pela crítica do cristianismo (Brusotti, 2009, pp. 341-342). Um segundo momento, no início dos anos 30, é marcado pela leitura do livro de Oswald Spengler O declínio do ocidente (1918) e pela ideia do fim do pensamento filosófico ocidental (Ibid., p. 343). Ainda segundo Brusotti, a leitura de Nietzsche por Wittgenstein nos anos 30 é bastante marcada por esse livro, o que ele relaciona com a ideia de um "novo período da cultura", que, todavia, deve ser distinguido pela inversão de alguns valores e não da totalidade 
destes (Ibid., p. 345).

Esse aspecto se deixa refletir na sua acepção da filosofia. $\mathrm{Na}$ crítica e na solução proposta para ela e, novamente segundo Brusotti, por intermédio de Spengler, Wittgenstein, mesmo tendo Kant e Einstein como referenciais, permanece ligado à transvaloração dos valores (Brusotti, 2009, p. 347). Temas centrais, presentes nos Notebooks, indicam importante ocupação de Wittgenstein com temáticas próximas à filosofia de Nietzsche, tais como as das noções de sujeito, de vontade e de valor, marcada por clara significação ética (Lewy, 2007, pp. 41-43). Partindo-se destes pressupostos, é possível associar a crítica da filosofia feita por Nietzsche com a exercida por Wittgenstein, sob o ponto de vista da linha de continuidade existente entre elas e reconhecida pelo filósofo austríaco ${ }^{3}$.

\section{A questão do sentido}

Um primeiro aspecto a ser observado com respeito à filosofia do primeiro Wittgenstein é o seu inerente aspecto ético (Diamond, 2000, p. 152). Todavia, o que Wittgenstein compreende como um posicionamento ético relacionado à filosofia envolve uma teoria do uso linguístico, mais especificamente a reflexão acerca do sentido e do não sentido das proposições significativas (Lewy, 2007, p. 9). São as reflexões acerca da questão do sentido que elucidam a dimensão ética de seu pensamento, pois buscam mostrar de quais modos essa temática pode ser pensada e o modo de referência a ela. Assim, é possível indicar aqui dois aspectos que são centrais para a argumentação: 1. O Tractatus

\footnotetext{
${ }^{3}$ Tal aproximação já é feita por Arthur C. Danto, no seu Nietzsche as Philosopher, de 1951, todavia relacionando Nietzsche com a filosofia do "segundo" Wittgenstein.
} 
Logico-Philosophicus, segundo uma reflexão acerca dos pressupostos lógicos do uso linguístico, indica tanto os limites deste uso na filosofia, mas também na ciência (Spica, 2009, p. 15). 2. A indicação da correta, mas irrealizável, tarefa da filosofia, de fazer uso apenas de proposições verdadeiras - e assim se aproximar das ciências naturais - revela também o limite destas, que não podem ultrapassar o uso de proposições referenciais.

Como é sabido, para o primeiro Wittgenstein, através da figuração é que nós produzimos modelos da realidade (TLP § 2.12). Na figuração, os elementos substituem os objetos (TLP § 2.131) e dessa relação decorre seu caráter, falso ou verdadeiro (TLP § 2.222). A figuração é lógica e "contém a possibilidade de situação que ela pensa" (TLP § 3.02). A proposição é a expressão sensível e perceptível do pensamento (TLP § 3.1) e emissário último de sentido da linguagem, capaz de expressar com sentido o pensamento. Ela, todavia, não contém o projetado (TLP § 3.12 ), pois nela está contida a forma de seu sentido, mas não o conteúdo (TLP § 3.13).

Esses pressupostos são formulados e mobilizados por Wittgenstein a partir de sua interpretação do uso proposicional das ciências naturais (TLP § 4.111) e têm por finalidade esclarecer que uma proposição cujo sentido se refere apenas às suas possibilidades lógicas, ao seu espaço lógico de formulação, não é necessariamente uma proposição sem sentido, pois a lógica independe do mundo, mas não deixa de se relacionar com ele. Por isso, apenas as possibilidades de concatenação lógica das proposições não podem ser indicadas como critério de verdade (TLP § 5.55), mas tão-somente de sentido, pois as continuidades lógicas não necessitam de referencialidade. A forma lógica da proposição não cria nenhuma referência (Warren, 2011, p. 9), 
essa apenas pode ser indicada pela isomorfia entre as formas lógicas da linguagem e da efetividade. Um equívoco dentre os filósofos é confundir relações internas (lógicas) com relações entre estruturas dos fatos (externas) (TL $\S 4.122$ ). As primeiras não implicam na efetividade das designações de nomes e proposições, enquanto a segunda pressupõe a possibilidade da figuração de um estado de coisas efetivo.

Com efeito, a percepção das nuances de uma determinação do que venha a ser o mundo é evidente já no início do Tractatus. O mundo como caso ( Fall) (TLP § 1), como totalidade fatos (Tatsachen) e não de coisas (Dinge) (Ibid., § 1.1), mas como "espaço lógico" (Ibid., § 1.13), expressa claramente a significação das ciências estatístico-matemáticas na filosofia do primeiro Wittgenstein e o impede de restringir o conceito de objeto às referências espaço-temporais. Fatos (Tatsachen) dependem da existência (Bestehen) de estados de coisas (Sachverhalten), eles não podem mais ser reduzidos a dados sensíveis, mas também não a conceitos autoevidentes, como pensaram Frege e Russell (Faustino, 2006, p. 29).

Fatos são necessidades subjacentes a toda pretensão de sentido das proposições nas ciências naturais, e estas, se quiserem manter seu estatuto científico, não podem prescindir deles. É aí que se encontram as dificuldades do pensamento filosófico. Em sua pretensão à validade efetiva, a filosofia se voltou para universalismos cuja referencialidade é questionável e, assim, extrapolou os limites do uso lógico-linguístico referencial. Wittgenstein chama estes ultrapassamentos de "equívocos da lógica de nossa linguagem" (TLP. Prefácio, p. 9) e entende com isso o resultado de sequenciamentos lógicos-proposicionais no contexto dos usos linguísticos que, todavia, não possuem correlativos no mundo 
e em estados de coisas. Nisto está fundamentalmente colocado o posicionamento de Wittgenstein com respeito à filosofia com pretensões universalistas, expresso na afirmação, segundo a qual o Tractatus em sua plenitude poderia ser compreendido nas seguintes palavras: "O que propriamente se deixa dizer, se deixa dizer claramente; sobre aquilo que não se pode falar, a esse respeito é necessário calar-se" (Ibid.).

Sob dois pontos de vistas diferentes, porém conjugados, o Tractatus indica duas dimensões do pensamento. Uma delas precisa, de algum modo, indicar (anzeigen) algo do mundo a partir da pressuposição de referência dos nomes e do sentido das proposições elementares (TLP $\S 6.124$ ), a outra indica a dimensão do uso arbitrário, não necessariamente comprometido com o uso tautológico. Por esse motivo, torna-se claro que "a comprovação lógica de uma proposição com sentido (sinnvoll) e a comprovação na lógica necessitam ser coisas totalmente distintas" (TLP § 6.1263). A filosofia, a estética, a ética e o pensamento religioso pertencem a esta segunda dimensão e ultrapassam injustificavelmente os limites do uso linguístico norteado pela comprovação (Beweis). Por outro lado, o uso linguístico referencial não pode jamais abandonar seu campo de atuação (Badiou, 2008, p. 11), caso contrário ele se torna místico e precisa, neste caso, afastarse da forma tautológica.

Há, porém, ainda um aspecto posto no prefácio do Tractatus que é significativo mencionar. Ele reside no fato de Wittgenstein assinalar a verdade dos pensamentos mencionados. Esta, que neste momento lhe parece intocável e definitiva no sentido da solução dos problemas filosóficos, se refere decisivamente à interpretação lógica do uso linguístico. A verdade anunciada por Wittgenstein está muito mais associada à solução de um 
determinado problema, propriamente o do desejo de universalidade e de atemporalidade da filosofia metafísica, que à pretensão de estabelecimento de uma nova verdade universal. Isso se dá por vários fatores, dos quais eu gostaria de mencionar dois. 1. Ocorre e, segundo Wittgenstein, é necessário atentar para isso, que continuidades lógicas não podem criar o seu próprio sentido, ou seja, criar um estado de coisas a partir de sua possibilidade de ser pensada. A linguagem produz afigurações (Abbildungen) do mundo, que podem ser corretas (richtig) ou falsas (TLP $\S$ 2.17), mas isso no sentido da referência a um estado de coisas ou efetividade (TLP § 2.223) e não à sua estrutura lógica, pois esta pode produzir afigurações falsas (TLP § 2.173): "Uma imagem verdadeira a priori não existe" (TLP $\S 2.224$ ). Desse modo, o equívoco com respeito à lógica da linguagem repousa na carência de compreensão das formas de seu uso em nossas relações figurativas com o mundo. 2. A filosofia metafísica oblitera a diferenciação entre organização lógica de pensamentos, que é intransponível (TLP $\S 3.031$ ), e a diferença entre o modo de relação destes pensamentos e a sua relação a posteriori com a efetividade. Ela transpõe os limites da lógica entendida como teoria das formas e se enclausura no contexto do uso linguístico auto evidente, sem perceber que leis lógicas não podem se subordinar a leis lógicas (TLP § 6.123), assim como oblitera a distinção entre lógica e uso proposicional (TLP $\S$ 6.1232). Isso significa deixar de perceber que proposições simplesmente nomeiam as coisas, elas não às dizem (TLP § 3.221), e que, no contexto do uso linguístico, as possibilidades de nomeação são infinitas. Desse modo, a maioria das proposições e questões referentes à filosofia não são falsas, mas contrassensos (unsinnig) (TLP § 4.003), elas não possuem nenhum outro significado além 
daquele que lhes cabe no interior do uso lógico da linguagem.

\section{Filosofia, ética e sentido}

A partir destes dois pontos, é possível uma aproximação mais específica de aspectos centrais da interpretação de Wittgenstein da função da filosofia. Isso diz respeito à diferenciação entre lógica proposicional e uso proposicional na filosofia. Se para o primeiro Wittgenstein proposições filosóficas não são significativas e nem podem dizer à lógica que possibilita mencioná-las (TLP § 4.12), o que resta à filosofia, a partir do uso proposicional estabelecido pelas ciências naturais (TLP § 4.112), é uma atividade elucidativa, no sentido do "esclarecimento lógico de pensamentos". Ela não pode constituir um pensamento lógico normativo, pois a proposição não é uma representação, mas uma descrição bipolar do mundo e pode ser verdadeira ou falsa (Spica, 2009, p. 12). Ela deve separar o pensável do impensável, tendo em seu horizonte as ciências naturais, mas sem a possibilidade de equiparar-se a elas (TLP § 4.111), estipulando assim o indizível e o dizível neste contexto (TLP § 4.113). "A finalidade da filosofia é o esclarecimento lógico dos pensamentos", ela não é ou pode ser uma teoria prescritiva (Lehre), mas torna-se uma atividade, que consiste essencialmente em elucidações, no aclarar de proposições (Ibid., § 4.112) significativas. Desse modo, ela "delimita a área disputável da ciência natural" (TLP § 4.113) e delimita internamente o pensável, por meio do impensável (TLP $\S 4.114)$.

Para Wittgenstein, "o sentido da proposição é a sua concordância e discordância com a possibilidade de existência e não existência dos estados de coisas" (TLP § 4.2). Uma proposição verdadeira possui sentido, ou seja, não apenas significado 
formal, mas real. Diferentemente da lógica, a realidade do significado da proposição se confirma na própria efetividade, e não tautologicamente. Caso contrário, poder-se-ia recair no equívoco metafísico de querer interpretar uma figuração lógica do mundo com o próprio mundo, mas isso não pode ser feito, haja vista que o limite do mundo é estabelecido para nós no limite do uso linguístico utilizado para se referir a ele e, nessa relação, ele jamais é dito em sua totalidade.

\section{A questão do sentido das proposições éticas}

Partindo do acima exposto, podemos nos aproximar da impossibilidade de justificação de um posicionamento filosófico doutrinal segundo Wittgenstein. A questão do sentido do uso proposicional com sentido (Sinnvoll) possibilita que se entenda os seus pressupostos no que se refere à impossibilidade de proposições éticas deterministas (TLP $\S 6.42$ ), pois, segundo ele, as proposições não podem exprimir algo mais elevado (höheres) que o mundo, o que determina o caráter transcendental da ética e a associa à estética (TLP § 6. 421).

Transcendental significa aqui estar fora do mundo, para além do estado das coisas (TLP § 6. 41). As proposições éticas de caráter normativo (sollen) têm os seus significados fundados no uso linguístico unicamente, não são descritivas, mas prescritivas. A proposição possui em si propriedades do mundo, mas não é, ela mesma, um fato afigurado. Em outras palavras, elas pressupõem uma justificação de sentido meramente auto evidente e não efetivo. Proposições éticas universalistas não descrevem um estado de coisas, mostram um determinado uso linguístico, cuja lógica, em sua forma, não está subordinada ao mundo. Desse modo, elas permanecem, em suas pretensões de validade efetiva, 
sem sentido, pois o estado de coisas ao qual elas se referem efetivamente não existe (Diamond, 2000, p. 171). A negatividade desse posicionamento não significa, porém, uma objeção decisiva com respeito a todo o pensamento ético (Rentsch, 1999, p. 357). Se Wittgenstein mostra a impossibilidade de uma fundamentação científica do uso proposicional no contexto de proposições morais e metafísicas, o direcionamento ético de seu escrito se mostra precisamente na evidenciação desta impossibilidade. Nesse sentido, três aspectos devem ser ressaltados: 1 . Wittgenstein não empreende a sua crítica no sentido de criar as possibilidades para um novo uso proposicional normativo, pois esta pretensão se mostra para ele como carente de sentido. 2. O posicionamento que afirma a existência do ético é interpretado decisivamente como referência lógico-gramatical não efetiva. 3 . Devido a isso, o termo ética, ao qual Wittgenstein se refere, diz respeito ao seu novo posicionamento referente à teoria da significação, que exclui toda pretensão normativo-doutrinal. Isso acaba por revelar uma dimensão antropológica de sua reflexão e a importância da própria ética no seu interior (Rentsch, 1989, p. 178).

Trata-se, por conseguinte, de uma tentativa de ressignificação do conceito de ética, que adquire o caráter de atividade elucidativa e não mais normativa. Diferentemente dos problemas aparentes da filosofia, a ética não é abandonada no Tractatus, ela deve apenas ser redirecionada e não mais aspirar mencionar algo além do mundo, deve ser pensada como atitude, como atividade (Crary, 2007, p. 217). Isso porque a teoria do uso proposicional leva Wittgenstein a compreender a impossibilidade de expressão com sentido tanto da ética como da religião (De Angelis, 2007, p. 105). Linguagem, normativamente pensada, pode ex- 
pressar, afigurar fatos ou estados de coisas, mas a afiguração é sempre contingente (Ibid., p. 108). Quando são extrapolados os limites desta relação, ultrapassa-se imediatamente o âmbito dos critérios de verdade e então adentra-se nos domínios valorativos, que não são objetiváveis. É por este motivo que a filosofia não pode ser pensada como doutrina, mas sim como atividade de esclarecimento de conceitos.

As proposições utilizadas pelas éticas universalistas se referem a objetos metafísicos, que, por não estarem no mundo, não podem ser referenciados. Enunciados éticos extrapolam o domínio dos estados de coisas, por isso a reflexão ética pode ser identificada com a estética, que não é norteada pelo pressuposto de verdade e é disposta em uma categoria extrasemântica. Influenciado e por meio de uma rearticulação crítica do princípio da filosofia moral kantiana (Marques, 2006, p. 64), segundo o qual o princípio da moral deve ser independente da contingência empírica, Wittgenstein parte do princípio, segundo o qual o ético, em sentido universalista, não pode ser dito (TLP $\S 6.42$, 6.421). Isso não significa que a questão ética não exista, apenas que ela não pode ser mencionada referencialmente, motivo pelo qual ela é caracterizada como transcendental (TLP § 6.421).

\section{Nietzsche, Wittgenstein e a desconstrução linguística da ética universalista}

A argumentação aqui apresentada tentou mostrar como as críticas de Nietzsche e de Wittgenstein à interpretação da linguagem pela filosofia buscam desconstruir a tendência metafísica de considerar a linguagem como capaz de representar uma realidade exterior a ela. Em ambos os autores esta empreitada não é interna à filosofia, não se dá no sentido de uma correção 
interna dos enunciados filosóficos. Para ambos, a análise do uso linguístico na filosofia é feita do exterior, compreendendo-o como uma especificidade. Nesse sentido, seus esforços significam primeiramente a indicação da inexecutável pretensão da metafísica de alcançar um conhecimento final da efetividade e a indicação de que esta aspiração apenas pode ser tomada como exequível, devido a uma interpretação metafísica da linguagem e a canonização de certos aspectos e usos de linguísticos.

Com respeito às pretensões morais da filosofia, isso significa a crítica e o distanciamento de toda aspiração em legitimar posicionamentos normativos universalistas. A linguagem não necessariamente comunica uma realidade referenciável, e, quando o faz, produz apenas uma representação da efetividade, a qual esta não é redutível. O processo de formulação de nossas representações da efetividade não pode, porém, ser descrito, ele pode apenas ser mostrado, seja como gramática, seja como perspectiva genealógica. Nesse sentido, dois fatores significativos que aproximam Nietzsche e Wittgenstein podem ser mencionados: 1. As reflexões de ambos são responsáveis pelo solapar das últimas pretensões metafísicas da filosofia com anseios científicos e universalistas. 2. Nietzsche e Wittgenstein são autores que chamam a atenção para a necessidade de existência de outras possibilidades de pensamento no que concerne à vida humana, pois ambos percebem as dificuldades de transposição de pressupostos e usos linguísticos a outros campos de significação. Como se tentou mostrar, enquanto Nietzsche parte de um horizonte marcado pela ascensão das ciências naturais, o que o remete a uma interpretação naturalista da linguagem, a análise do uso linguístico em Wittgenstein está muito mais relacionada com a questão da lógica de seu uso. Todavia, ocorre na filosofia de ambos a 
tendência a uma interpretação da linguagem, caracterizada pelo afastamento com respeito à interpretação efetuada pela metafísica. Em ambos há um distanciamento da perspectiva estabelecida na filosofia desde Platão (Borsche, 1994, p. 126), segundo a qual, a linguagem seria uma espécie de instrumento da racionalidade concernente ao alcance e à transmissão de verdades assentes. Para Nietzsche, um dos traços de sua filosofia é o do esforço para libertar a filosofia da sedução da moral, a Circe da filosofia (M/A, prefácio § 3). Devido a isso, a atividade filosófica se torna uma atividade interpretativa, apartada de toda crença na posse de uma verdade definitiva, uma atividade não dogmática por excelência.

Partindo-se da confirmação documental do já mencionado contato de Wittgenstein com projeto de Nietzsche de uma transvaloração dos valores e pela proximidade temática de problematizações feitas pelo autor do Tractatus no período de elaboração dessa obra (Lewy, 2007, p. 31), pode-se especular acerca da significação de problemáticas da filosofia nietzschiana para Wittgenstein (Badiou, 2008, p. 15). Entretanto, como também já indicado, em Wittgenstein a questão do valor (da ausência de valor) do mundo (TLF § 6.41) não poder ser, sem graves prejuízos interpretativos, distanciada de sua crítica do uso linguístico tradicional na filosofia e por isso deve ser claramente diferenciada da perspectiva de Nietzsche. A afirmação de Wittgenstein de que o pensamento moderno se baseia no equívoco, "de que as assim chamadas leis da natureza seriam o esclarecimento das ocorrências naturais" (TLP $\S 6.372$ ), possui uma perspectiva outra que consideração fisio-psicológica da atividade metafórica da linguagem em Nietzsche. Mas elas possuem significativos pontos de aproximação. Em ambos a proximidade de pontos de 
vista redunda na percepção da impossibilidade de proposições éticas em sentido absoluto, pois as leis das ocorrências morais não podem ser determinantemente indicadas. Em seus escritos posteriores Wittgenstein parece se manter fiel a este princípio (Crary, 2007, p. 218). A interpretação da significação ética em sua filosofia parece então permanecer inalterada. Ampliada, ela insiste em indicar o mau uso linguístico na filosofia, e assim continua a tentar evidenciar que muitos problemas decisivos para o pensamento filosófico tradicional ocorrem precisamente quando a linguagem festeja (feiert) e não mais percebemos que o nomear é quase que um batizar o objeto (IF § 38), mas nunca a expressão da sua "verdade". Desse modo, os novos acontecimentos na filosofia devem ser compreendidos a partir do descobrimento de algumas más ausências de sentido, e de bolhas, que o entendimento buscou em seu apressado passeio (Anrennen) junto às fronteiras da linguagem. Essa descoberta é positiva, pois as bolhas "evidenciam o valor de cada descoberta" (IF § 119) e devem levar a filosofia a tornar evidente a possibilidade de novas descobertas e invenções (Ibid., § 126), afastando-a de todo dogmatismo que até então a caracterizou. Quanto a isso, Nietzsche e Wittgenstein parecem concordar plenamente.

\section{Referências bibliográficas}

BADIOU, A. Wittgensteins Antiphilosophie. Zürich-Berlin: Diaphanes, 2008.

BARRENECHEA, M. A. et al. (orgs.) Nietzsche e as ciências. Nietzsche, a linguagem e a sofística. Rio de Janeiro: Sette Letras, 2011, pp. 242-247.

BERTINO, A. C. "As with Bees?" Notes on Instict and language in Nietzsche and Herder. In: CONSTÂNCIO e BRANCO 
(orgs.). Nietzsche on Instict and Language. Berlin/New York: Walter De Gruyter, 2011, pp. 2-34.

BORNAMANN, F. "Zur Chronologie und zum Text der Aufzeichnungen von Nietzsches Rhetorikvorlesungen". NietzscheStudien, Bd. 26, 1997, pp. 491-500.

BORSCHE, T. Natur-Sprache. Herder-Humboldt - Nietzsche. Berlin/New York: Walter de Gruyter, 1994, pp. 112-130. BRUSOTTI, M. "Wittgensteins Nietzsche. Mit vergleichenden Betrachtungen zur Nietzsche-Rezeption in wiener Kreis" $\mathrm{Ni}$ etzsche Studien, Berlin/New York:,Walter de Gruyter, Bd. 38, 2009, pp. 335-362.

CRARY, A. Wittgenstein and the Moral life: Essays in Honor of Cora Diamond. Cambridge: MIT Press, 2007.

CRAWFORD, C. "The beginnings of Nietzsche's theory of Language". Monographien und Texte zum Nietzsche - Forschung, Berlin - New York: Walter de Gruyter, Bd. 19, 1988.

DIAMOND, C. The realistic spirit. Wittgenstein, Philosophy, and the Mind. Cambridge, Massachusetts, London: Massachusetts Institut of Technoogy (MITpress), 1995.

DEANGELIS, W. J. Ludwig Wittgenstein. A cultural point of View. Burlington: Ashgate, 2007.

FAUSTINO, S. A experiência indizivel: uma introdução ao Tractatus de Wittgenstein. São Paulo: Editora UNESP, 2006. HALLER, R. "A ética no pensamento de Wittgenstein." Estudos avançados. São Paulo, vol. 5, n. 11, 1991, pp. 45-56.

LAMPERT, L. Nietzsche's Task. An interpretation of Beyond Good and Evil, 2001.

LAMPERT, T. Wittgensteins Physikalismus. Paderborn: Mentis Verlag, 2000.

LOPES, R. Elementos de retórica em Nietzsche. São Paulo: 
Loyola, 2006.

MARQUES, E. "Observações acerca do ético na filosofia do primeiro Wittgenstein". Revista ETHICA, Rio de janeiro, v. 13, n. 2, 2006, pp. 59-68.

NIETZSCHE, F. Sämtliche Werke. COLLI; MONTINARI (ed.). Kritische Gesamtausgabe (KGW). Berlin-Nova York: de Gruyter/DTV, 1980.

. Sämtliche Werke. Kritische Studienausgabe (KSA). COLLI;

MONTINARI (ed.). Munique: de Gruyter/DTV, 1980.

RENTSCHE, T. Negativität und praktische Vernunft. Frankfurt am Main: Surkamp, 1999.

Heidegger und Wittgenstein. Existential- und Sprachanalysen zu den Grundlagen philosophischer Antropologie. Stuttgart: Ernst Klett Verlag, 1985.

SPICA, M. A. "A linguagem da ciência no Tractatus de Wittgenstein". Revista Intuíto, Porto alegre, vol. 2, n. 1, 2009, pp. 101-123.

WAISAMANN, F. Logik, Sprache, Philosophie. Prefácio de Moritz Schlick. Stuttgart: Reclam, 1976.

WITTGENSTEIN, L. Tractatus logico-philosophicus. Werkausgabe Band I. Frankfurt am Main: Surkamp, 1984.

. Tagebücher 1914 - 1916. Werkausgabe Band I. Frankfurt am Main: Surkamp, 1984.

- Philosophische Untersuchungen. Werkausgabe Band I.

Frankfurt am Main: Surkamp, 1984.

. Briefwechsel. Frankfurt am main: Surkamp, 1980.

ZAMUNES, E., et al. (eds.) Ludwig Wittgenstein Lecture on Ethics. Mascerata, Italy: Verbarium/Quodiblet, 2007. 
